\title{
Erratum to: Therapeutic Consideration of Periappendiceal Abscess: an Evaluation of Non-surgical Treatment Followed by Minimally Invasive Interval Appendectomy
}

Yeong-Soo Jo, M.D., Song-Soo Yang, M.D., Yeong-Chul Im, M.D., Dong-Jin Park, M.D., Gyu-Yeol Kim, M.D.

Department of Surgery, University of Ulsan College of Medicine and Ulsan University Hospital, Ulsan, Korea

Corresponding author

Song-Soo Yang

Department of Surgery, Ulsan University Hospital, 290-3 Jeonhadong, Dong-gu, Ulsan 44033, Korea

Tel: +82-52-250-7722, Fax: +82-52-250-7350, E-mail: pau1913@hanmail.net

This is an Open Access article distributed under the terms of the Creative Commons Attribution Non-Commercial License (http:// creativecommons.org/licenses/by-nc/4.0/) which permits unrestricted non-commercial use, distribution, and reproduction in any medium, provided the original work is properly cited.

Invasive Surgery. All rights reserved.

J Minim Invasive Surg 2017;20(4):129-136

Name of hospital correction on page 130

It was printed as

OOO Hospital

Authors requested to change the name of the hospital to proper name.

Hospital name should be corrected as following.

Corrected hospital name

Ulsan University Hospital 